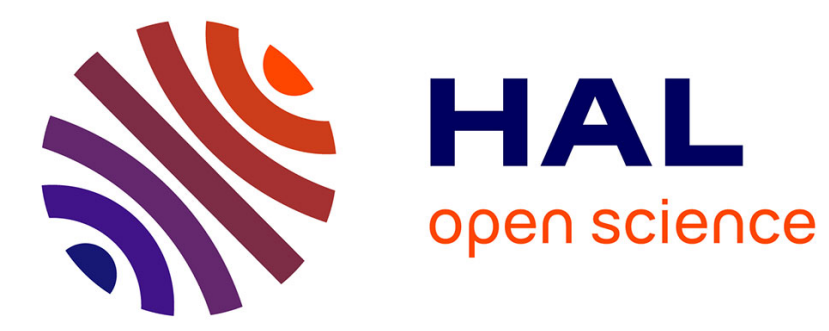

\title{
Willingness to Pay of Committed Citizens: A Field Experiment
}

Dominique Ami, Olivier Chanel, Frédéric Aprahamian, Robert-Vincent Joule, Stephane Luchini

\section{- To cite this version:}

Dominique Ami, Olivier Chanel, Frédéric Aprahamian, Robert-Vincent Joule, Stephane Luchini. Willingness to Pay of Committed Citizens: A Field Experiment. 2008. halshs-00289451

\section{HAL Id: halshs-00289451 https://shs.hal.science/halshs-00289451}

Preprint submitted on 20 Jun 2008

HAL is a multi-disciplinary open access archive for the deposit and dissemination of scientific research documents, whether they are published or not. The documents may come from teaching and research institutions in France or abroad, or from public or private research centers.
L'archive ouverte pluridisciplinaire HAL, est destinée au dépôt et à la diffusion de documents scientifiques de niveau recherche, publiés ou non, émanant des établissements d'enseignement et de recherche français ou étrangers, des laboratoires publics ou privés. 


\title{
Willingness to Pay of Committed Citizens: A Field Experiment
}

\author{
Dominique Ami \\ Frédéric Aprahamian \\ Olivier Chanel \\ Robert-Vincent Joulé \\ Stéphane Luchini
}

June 2008

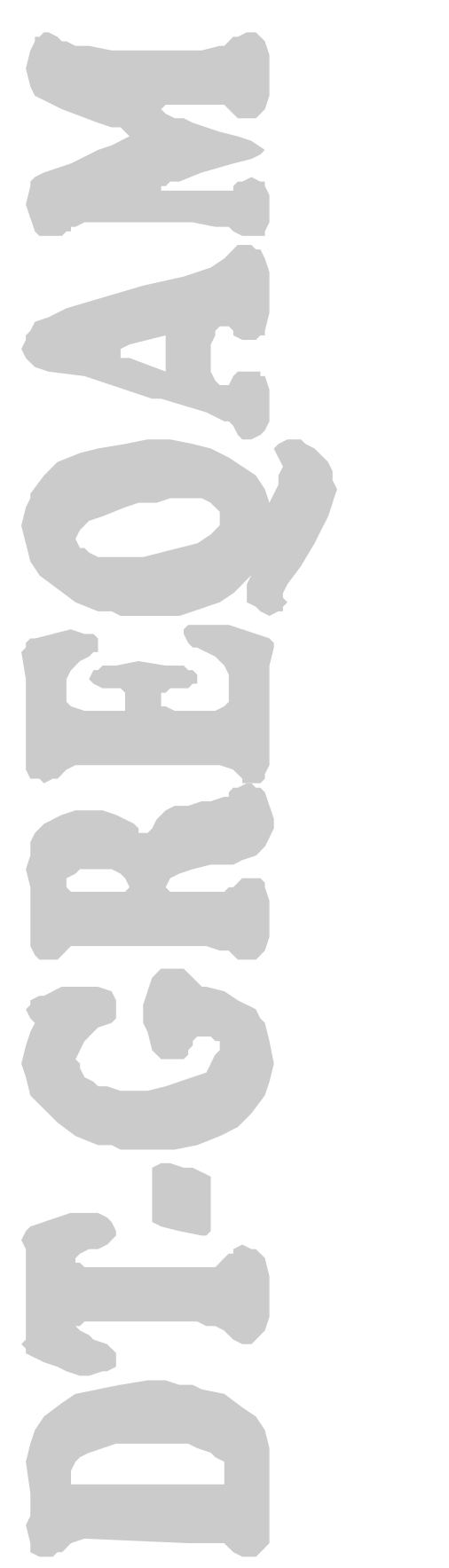




\title{
Willingness To Pay of Committed Citizens: A FIELD EXPERIMENT ${ }^{\ddagger}$
}

\author{
Dominique Ami ${ }^{1,2,3}$ Frédéric Aprahamian ${ }^{2,4}$ Olivier Chanel ${ }^{2,3,5}$ \\ Robert-Vincent Joulé ${ }^{6}$ Stéphane Luchini ${ }^{2,3,5}$ \\ ${ }^{1}$ Ecole Normale Supérieure de Cachan \\ ${ }^{2}$ Groupement de Recherche en Economie Quantitative d'Aix-Marseille (GREQAM) \\ ${ }^{3}$ Institut d'Economie Publique (IDEP) \\ ${ }^{4}$ Université du Sud-Toulon-Var \\ ${ }^{5}$ Centre National de la Recherche Scientifique (CNRS) \\ ${ }^{6}$ Laboratoire de Psychologie Sociale (LPS), Université de Provence
}

\section{May 2008}

\begin{abstract}
In this paper, we propose a behavioural approach to determine the extent to which the consumer/citizen distinction affects interpretations of monetary values. We perform a field experiment dealing with air pollution, where some (randomly selected) subjects are given the opportunity to behave politically by signing a petition for environmental protection prior to stating their private preferences in a standard contingent valuation exercise. We show that the petition has the potential to influence respondents' willingness to pay and that whether the effect is negative or positive depends on the degree of (dis)similarity between the petition and the scenario in which willingness to pay are elicited. We interpret the results using the theory of commitment borrowed from social psychology.
\end{abstract}

Keywords: Field Experiment, Citizen, Consumer, Contingent Valuation, Willingness to pay, Commitment, Air Pollution

JEL Classification: D6, C9

\footnotetext{
¥ Corresponding author: Stéphane Luchini. GREQAM, 2 rue de la Charité, F-13002 Marseilles, France, e-mail:stephane.luchini@univmed.fr. Financial support of French Research Ministry (n 045666 ACI Santé et Environnement) and technical support from the ProvenceAlpes-Côte-d'Azur Regional Council are gratefully acknowledged. We thank Alan Kirman, Jason Shogren, Marjorie Sweetko and Miriam Teschl for helpful comments and suggestions.
} 


\section{Introduction}

From the outset, the interpretation of respondents' behaviour in CV questionnaires has provoked debate. In particular, some authors have questioned the interpretation of respondents as consumers, proposing instead a more political interpretation of respondents as citizens (Nyborg 2000; Lewinson-Zamir 1998; Blamey et al. 1995). As citizens, the assumption is that respondents express political attitudes rather than expressing monetary values in line with consumer surplus (Orr 2007; Blamey 1998). This is primarily because attitudes do not correspond to people's consumer surplus (Kahneman and Sugden 2005). It has also been argued, for example, that respondents may adopt different 'roles' and that if they are in their citizen role, they may consider overall social welfare instead of their own needs or wants (Sagoff 1988). If this is the case, it would of course cast doubt on the use of respondents' answers in CV surveys in standard cost-benefit analysis (Nyborg 2000).

The question is how to operationalize the distinction between respondents in CV surveys as consumers and as citizens. One way of doing this is to adopt an ex-post approach that looks at determinants of observed behaviour, by correlating willingness to pay (WTP) values with appropriate attitudinal questions (Nunes and Schokkaert 2003). In this paper, however, we adopt an ex-ante and behavioural approach in the spirit of Boyce et al. (1992) that relies on commitment theory borrowed from social psychology (Kiesler 1971). Experiments on the social psychology of commitment have shown that when people agree to perform an initial action, even when it appears to be innocuous, this can have strong attitudinal and behavioural consequences (Kiesler and Sakumura 1966; Joule and Beauvois 1998). Our experiment follows this route in that some (randomly selected) subjects are given the choice to behave politically prior to stating their private preferences in a CV exercise. ${ }^{1}$ We call subjects who agree to perform the political action committed citizens and we compare their behaviour to that of a control group of respondents who merely answer the CV questionnaire directly.

Our field experiment focuses on a specific environmental issue: air pollution. First, some subjects are given the opportunity to sign a petition calling on (the 
then) future candidates in the French 2007 presidential election, to be held six months later, to take an official stand (regarding their program and respective commitment) on environmental preservation. Second, all subjects are asked to respond to a CV questionnaire aimed at eliciting willingness to pay for a reduction in air pollution. Our sample is therefore composed of two groups of subjects: one asked to sign a petition before performing the $\mathrm{CV}$ exercise and one performing this exercise directly.

We investigate the articulation between political behaviour and stated willingness to pay by examining values under three typical scenarios of the CV literature on air pollution: a new $d r u g$ that prevents adverse health effects of air pollution exposure for the respondent alone (Alberini et al. 2004; Krupnick et al. 2002), moving the whole household to an already less polluted city (Viscusi et al. 1988; Aprahamian et al. 2007) and new regulations on air pollution that will potentially increase market prices (Desaigues et al. 2007). One feature of these scenarios is they differ in scope. This means that benefits range from the individual (drug scenario) to the family level (move scenario) and up to the society level (regulation scenario). A second feature is that the drug scenario does not imply any particular measure to protect the environment whereas the two other scenarios do. The move scenario implies that local action has already been taken with the result that one of the locations has less air pollution. The regulation scenario presupposes national, or even international, measures to protect the environment.

The experiment took place over three days in October 2006 in the council chamber of Regional Council in the city of Marseilles which is equipped for electronic voting. It involved more than four hundred subjects under six sets of experimental conditions. Our results are as follows. First, more than eighty percent of subjects agreed to sign the petition when it was presented to them. Second, the petition had a significant, although varying, impact on subjects' willingness to pay. Econometric analysis shows that subjects who were offered the petition were more likely to pay more in the move and regulation scenarios. In the drug scenario, subjects were less willing to pay when they had been offered the petition prior to the valuation exercise. 
The paper is organized as follows. In the first section, we define our experimental hypotheses based on the social psychology of commitment. In the second section, we give a detailed description of the experimental design. The third section provides information on the sample characteristics and presents the empirical results. In the final section, we discuss the results and draw conclusions.

\section{Three experimental hypotheses}

Our first hypothesis is that subjects who have previously performed a political act, that is, who have signed the petition, will be willing to pay more for a good or a policy relevant to the protection of the environment than subjects who were not asked to sign the petition in the first place. Our second hypothesis is that subjects who have signed the petition will state a lower WTP in the drug scenario than subjects who have not been offered the petition. These two hypotheses can be understood in the light of the theory of commitment (Kiesler 1971; Joule and Beauvois 1998), whereby commitment means the "pledging or binding of the individual to behavioural acts" (Kiesler and Sakumura 1966, p. 349). Foot-in-the-door experiments are situations that typically produce this kind of commitment (Joule et al. 2007), by asking subjects to comply with an initial request and later on making a second request which is thematically in line with the initial request. In commitment theory in general, a first request acts as a commitment device that puts people in a certain mindframe regarding the action that is going to follow (Joule and Beauvois 1998). That is, when they are asked to comply with the second request, subjects may consider themselves as being the "kind of person [...] who does this sort of things" (Freedman and Fraser 1966, p.101) - in our case, a citizen who is concerned about environmental protection - because they have already complied with the initial request. ${ }^{2}$ "Being this kind of person" means that they are committed to a certain cause and hence are more likely to comply with the second request. Foot-in-the-door experiments have shown that subjects agree to a second request much more easily if they have already agreed to an initial request of a similar kind (see Freedman and Fraser 1966 for the original foot-in-the-door experiments, ${ }^{3}$ Burger 1999 and 
Joule and Beauvois 1998 for reviews, and Katzev and Wang 1994 and Wang and Katzev 1990 for applications to the environment).

In our experiment, we ask some subjects to sign a petition in favour of environmental protection and later on we ask subjects for their WTP on the one hand for living in a less polluted city (move) or for the implementation of new rules and laws against air pollution (regulation) and on the other hand for a drug (drug) that does not imply any protection of the environment but only reduces the effects of air pollution exposure on individual health. Because, "[c]ommitment in the guise of signing a petition [has] a powerful effect on the expression of attitude, leading to a more extreme attitude" (Kiesler, 1971, p. 79), we expect higher WTP values in the move and regulation scenarios (reflecting a more extreme attitude to environmental protection) but lower WTP values in the drug scenario, because the latter does not imply better protection of the environment. Indeed, taking the drug could even be taken to mean not protecting the environment, which is incompatible with being a citizen committed to environmental protection.

Our third hypothesis is that the impact of signing the petition on WTP should be different in the move and regulation scenarios. More precisely, the impact of the petition should be stronger in the regulation scenario and weaker in the move scenario. The foot-in-the-door literature shows that compliance with the second request increases with similarity to the initial request (Burger 1999; Joule and Beauvois 1998; Freedman and Fraser 1966). Similarity here means the same level of identification for the first and second request (Joule and Beauvois 1998). For example, in their second experiment, Freedman and Fraser (1966) consider initial requests which involve either putting a small sign for "safe driving" or "keeping California beautiful" on their window. In the second request, they ask subjects to install in front of their door a very large sign which says "Drive carefully". The initial request related to "safe driving" is said to have a higher degree of similarity with the second request. In our experiment, subjects are given the opportunity to sign a petition concerning nationwide environmental protection. This first act is a political commitment inducing a nationwide identification level of environmental protection. The move and regulation scenarios, however, induce different levels of identification regarding 
environmental protection. The move scenario implies a lower effect since only some local protective measures have been implemented. The regulation scenario implies a higher level because it presupposes national, or even international, measures to protect the environment and hence presents the highest degree of similarity with the petition. We therefore expect the highest effect in this particular scenario.

\section{Experimental design}

The experiment is a $2 \times 3$ design aimed at investigating the interplay between a specific political act and stated willingness to pay (WTP) for air quality improvements. Under the experimental conditions, subjects are either offered a petition before the valuation exercise or not, and are presented with three different scenarios.

Let us first describe the three scenarios. The empirical aim of the field experiment was to elicit willingness-to-pay for a decrease in air pollution. To this end, we considered three typical scenarios from the CV literature devoted to the valuation of air pollution effects. In the first scenario, called Drug scenario, we adopted the methodology proposed by Alberini et al. (2004) and Krupnick et al. (2002). The scenario presented subjects with a new drug that has to be taken on a monthly basis. This drug would reduce, by half, the long-term health effects of air pollution exposure. ${ }^{4}$ The direct benefits of this new drug are therefore essentially at the individual level $l^{5}$ and air pollution itself is not reduced (see Appendix A for the scenario). The second scenario, called Move scenario (Viscusi et al. 1988; Aprahamian et al. 2007), is a choice of moving with the subject's household to one of two cities which have exactly the same characteristics (city size, housing, weather, public services etc.) apart from the cost of living and the level of air pollution. ${ }^{6}$ By moving to a less polluted place, the subject was offered the opportunity to improve air quality for him/herself and other members of his/her household (see Appendix B for the scenario). We borrowed the third scenario, called Regulation scenario, from the New Energy Externalities Developments for Sustainability project (NEEDS) supported by 
the European Commission (Desaigues et al. 2007). This scenario involves new rules and laws to be applied to polluting firms and activities (industries, transport, etc.). Since the introduction of these new laws and rules would increase the cost of living, through market prices, the subject is asked to state the maximum s/he would be willing to pay each month to implement this policy. ${ }^{7}$ In this scenario, not only the subject and his/her family but also the whole community would benefit from the implementation of this new policy (see Appendix $\mathrm{C}$ for the scenario). It is worth noting that the changes in air pollution proposed in each scenario were identical: air pollution health effects reduced by half with the same situation of reference.

Respondents were recruited through advertisements in local newspapers and on local TV news - the survey was described as being about quality of life. Each participant was paid $€ 20$ (about US $\$ 26$ ) in gift vouchers. Respondents were unaware of the exact topic of the survey prior to the experiment. The experiment was conducted in the Regional Council council chamber. The voting room is equipped with an electronic voting system that allows some of the information to be collected in real time from up to 120 participants and ensure that experiments are carried out in the same manner in each session. On the first day, three sessions were implemented, each devoted to one particular scenario (scenarios were drawn randomly). On the second day, three sessions were also implemented in the same way but, prior to the CV experiment itself, subjects were asked to sign a petition. ${ }^{8}$ The petition asked future candidates in the 2007 presidential election to take an official stand concerning environmental preservation. ${ }^{9}$ Three students from the Department of Psychology, who presented themselves as apolitical students, asked subjects to sign the petition before entering the voting room. The students were given a script to learn by heart. The script was therefore the same each time they presented the petition to subjects (see appendix D for a full translation). To correlate the information on subjects' willingness to sign the petition with their respective answers in the $\mathrm{CV}$ experiment, we assigned to each subject a number corresponding to their voting seat when they registered. Two other experimenters noted the number worn on the subject's chest, and whether or not $\mathrm{s} /$ he signed the petition (CV answers were also identified using this number). ${ }^{10}$ Our design thus allowed us 
to keep track of subjects throughout the experimental procedure.

The CV experiment itself was divided into three parts. The first part of the experiment contained a self-administered survey with questions on the socioeconomic background of the respondent and knowledge of air pollution. Thereafter the scenario was presented to respondents. Their willingness to pay regarding air pollution was elicited using a sequential procedure. In this procedure, scientific information on the effects of air pollution ${ }^{11}$ and information on other subjects' willingness to pay (gathered through the electronic voting system) was progressively introduced. Finally, subjects were asked about their willingness to pay for a reduction in the effects of air pollution in an open-ended question at the end of the sequential procedure (see Chanel et al. 2006 for a complete description of the elicitation procedure). In the present article, we focus on the answer to the final open-ended elicitation question. Follow-up questions allowing protest responses to be identified were also provided at the end of the experiment.

The CV experiment provides us with two different tracks to investigate the impact of the political action taken through the petition. The first track is whether exposure to the petition affects the likelihood of protest responses, and if so, whether this varies with the scenario. The second track is whether taking a political action before the valuation exercise affects willingness to pay.

\section{Results}

The experiment was carried out in October 2006 with a total number of 441 participants for the six sessions. As registration via the Public Economics Institute website or phoneline was not mandatory, the total number of participants in each session varies (see Table 1 for the number of subjects in each session and in Appendix E for the sample means and standard deviations of key socioeconomic variables). 
Table 1: Summary statistics by treatment condition and scenario $(N=441)$

\begin{tabular}{llccc}
\hline \hline Scenario & & Standard & Petition & Both \\
\hline Drug & $\sharp$ of respondents & 49 & $117(82.9 \%$ signatures) & 166 \\
& $\sharp$ of protests (rate) & $8(16 \%)$ & $20(17 \%)$ & $28(16.9 \%)$ \\
& Mean WTP (sd) & $€ 30.22(8.18)$ & $€ 16.62(1.67)$ & $€ 23.01$ \\
& Mean WTP/Income & $3.77 \%$ & $1.51 \%$ & $2.26 \%$ \\
Move & $\sharp$ of respondents & 86 & $63(84.1 \%$ signatures) & 149 \\
& $\sharp$ of protests (rate) & $3(3.5 \%)$ & $0(0 \%)$ & $3(2.0 \%)$ \\
& Mean WTP & $€ 94.76(12.64)$ & $€ 72.62(9.25)$ & $€ 83.78$ \\
& Mean WTP/Income & $8.48 \%$ & $8.98 \%$ & $8.87 \%$ \\
Regulation & $\sharp$ of respondents & 63 & $63(79.3 \%$ signatures) & 126 \\
& $\sharp$ of protests (rate) & $2(3.2 \%)$ & $1(1.6 \%)$ & $3(2.4 \%)$ \\
& Mean WTP & $€ 24.66(3.58)$ & $€ 36.85(5.03)$ & $€ 27.13$ \\
& Mean WTP/Income & $2.73 \%$ & $6.22 \%$ & $4.63 \%$ \\
\hline All scenarios & $\sharp$ of respondents & 198 & $243(82.3 \%$ signatures) & 441 \\
& $\sharp$ of protests (rate) & $13(6.5 \%)$ & $21(8.6 \%)$ & $34(7.8 \%)$ \\
& Mean WTP (sd) & $€ 57.34(6.54)$ & $€ 38.16(3.42)$ & $€ 46.88$ \\
& Mean WTP/Income & $4.82 \%$ & $5.56 \%$ & $5.30 \%$ \\
\hline \hline
\end{tabular}

\subsection{Unconditional petition effect}

Table 1 presents descriptive statistics of the experiment. A large proportion of respondents agreed to sign the petition asking the future candidates to take an official stand in their program regarding environmental preservation: $82.3 \%$. This is not surprising given that, when the experiment took place, this issue was receiving a lot of attention in the French media. Moreover, numerous studies in social psychology show that when people are given the opportunity to perform a small inexpensive act (in our case, signing a petition related to a current issue and involving no monetary cost), many people freely choose to do so (Katzev and Wang 1994; Pallack et al. 1980; Wang and Katzev 1990; Joule and Beauvois 1998; Girandola and Roussiau 2003). There are no significant statistical differences in signature rate between the different scenarios ( $p$-values of two-sample tests for equality of proportions range from 0.64 to 0.99 ).

Protest responses correspond to respondents expressing null WTP and giving a reason in closed-ended debriefing questions or open comments that can 
be described as protests. ${ }^{12}$ The number of protests differs between the $d r u g$ scenario and the move and regulation scenarios ( $p$-values lower than 0.0001 for both comparisons). It is markedly higher for the former, regardless of whether the petition has previously been offered (16.9\% vs $2.0 \%$ for move and $2.4 \%$ for regulation on average). There is also a small but non-significant decrease in protest responses when the petition has been offered, for the move and regulation scenarios.

Let us now consider the WTP statistics. ${ }^{13}$ Table 1 shows first that mean WTP differs depending on which scenario has been implemented. The mean WTP obtained in the move scenario, taking both with and without petition responses together $(€ 83.78)$, is significantly and substantially higher than in the drug (€23.01 with $p<0.0001)$ and the regulation (€27.13 with $p<0.0001$ ) scenarios. There are no significant differences between mean WTP of the drug or regulation scenarios $\left(p=0.206^{14}\right)$. Second, the impact of the petition on mean WTP differs according to the scenario evaluated in the session. The impact of the petition on mean WTP is negative in the $\operatorname{drug}(p=0.043)$ and move $(p=0.092)$ scenarios, whereas it is positive in the regulation scenario $(p=0.034)$. However, such significant differences in mean WTP could be due to the heterogeneity of respondents between each session. One primary source of heterogeneity in respondents' WTP is income. Table 1 also provides mean WTP divided by income to account for potential heterogeneity. Results show that the differences in WTP induced by the petition also apply to the drug $(3.77 \%$ vs. $1.51 \%-p=.054)$ and regulation $(2.73 \%$ vs. $6.22 \%-p=.038)$ scenarios whereas the impact of the petition on the ratio of WTP over income in the move scenario is not significant $(8.48 \%$ vs. $8.98 \% p=.204)$.

\subsection{Conditional petition effect}

We have so far only considered differences in mean WTP or taken into account respondents' income when analysing differences in mean. Confirmation that the results still hold when overall potential heterogeneity of respondents is taken into account is provided by regressing explanatory variables as well as experimental condition variables on the logarithm of WTP both on the subsample of 
Table 2: Semi-logarithmic WTP Model $(N=341)$

\begin{tabular}{|c|c|c|}
\hline Variable & $\begin{array}{l}\text { Parameter } \\
\text { Estimate }\end{array}$ & $(p$-value $)$ \\
\hline \multicolumn{3}{|l|}{ Subject's characteristics } \\
\hline Constant term & .4632 & $(0.521)$ \\
\hline Male & -.0585 & $(0.577)$ \\
\hline $\log (A g e)$ & .0129 & $(0.948)$ \\
\hline$B a c$ & .2545 & $(0.041)^{\star \star}$ \\
\hline $\log (N P$ ers $)$ & .1287 & $(0.200)$ \\
\hline $\log ($ Income $)$ & .2055 & $(0.004)^{\star \star \star}$ \\
\hline LiveMars & -.2042 & $(0.091)^{\star}$ \\
\hline Owner & .0944 & $(0.423)$ \\
\hline PrivHealthIns & .3419 & $(0.016)^{\star \star}$ \\
\hline GoodQualiMars & -.3067 & $(0.081)^{\star}$ \\
\hline KnowAir & -.0418 & $(0.745)$ \\
\hline KnowAtmo & .0328 & $(0.818)$ \\
\hline KnowAirmaraix & -.1966 & $(0.115)$ \\
\hline NevSortWaste & -.2969 & $(0.013)^{\star \star}$ \\
\hline$H a b$ & .0803 & $(0.428)$ \\
\hline FreshAir & .2785 & $(0.048)^{\star \star}$ \\
\hline Smoker & .0768 & $(0.637)$ \\
\hline Goodhealth & .2392 & $(0.036)^{\star \star}$ \\
\hline \multicolumn{3}{|l|}{$\underline{\text { Scenario effects }}$} \\
\hline Move & 1.1563 & $(0.000)^{\star \star \star}$ \\
\hline Regulation & .2639 & $(0.203)$ \\
\hline \multicolumn{3}{|l|}{ Petition effects } \\
\hline Petition $\times$ Drug & -.2890 & $(0.168)$ \\
\hline Petition $\times$ Move & .1773 & $(0.316)$ \\
\hline Petition $\times$ Regulation & .3399 & $(0.035)^{\star \star}$ \\
\hline Wald joint nullity test: $p<$ & 0001 & \\
\hline
\end{tabular}

respondents who signed the petition and on those who only answered the CV questionnaire. ${ }^{15}$ Table 2 contains the estimation results (the first column contains the parameter estimates and the second column contains the associated $p$-values). The set of covariates is left relatively large to avoid misspecification biases. 
Figure 1: Percentage changes in WTP values

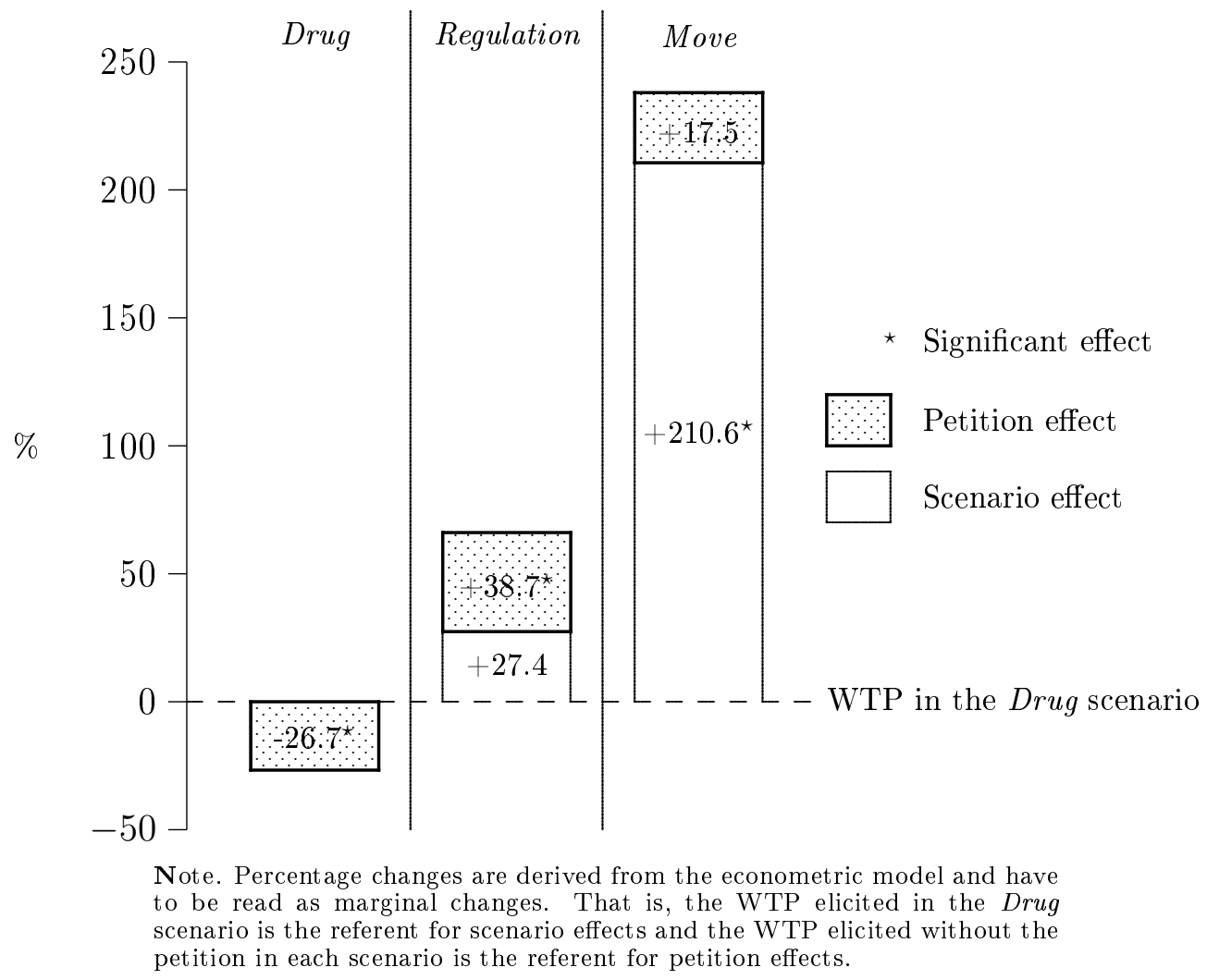

Regressing logarithm of WTP on the various explanatory variables gave the following results. In particular, the logarithm of income is highly significant, indicating that the higher the income, the higher the WTP. This is reassuring (see Hausman 1993 for a discussion on this issue) and provides evidence of the validity of the stated preference experiment (which Bishop and Woodward 1995 defined as theoretical construct validity). Having Senior High School Education level (Bac), Having a complementary private health insurance (PrivHealthIns), Going to the countryside regularly to breath pure air (FreshAir) and Declaring good or very good health (GoodHealth) have a positive impact on WTP. Living in Marseilles (LiveMars), Declaring that air quality in Marseilles is good (GoodQualiMars) and Never sorting waste for recycling (NevSortWaste) have a negative impact on WTP values. Interestingly, the latter is also connected to social awareness.

We now describe the effect of the scenarios on WTP values (referent is 
the drug scenario). Econometric results confirm the unconditional mean tests: WTP values elicited in the move scenario are higher than those elicited in the drug scenario $(p<0.001)$. WTP values elicited in the regulation scenario are higher, but not significantly, than those elicited in the $d r u g$ scenario $(p=.203)$. The percentage changes in WTP values induced by the move and regulation scenarios with respect to WTP elicited in the drug scenario (referent) are presented in Figure 1. ${ }^{16}$ In particular, it shows that WTP elicited in the move scenario are in average $210.6 \%$ higher than those elicited in the $d r u g$ scenario.

Three different dummies are introduced in the WTP equation to investigate the effect of signing the petition on WTP values - one for each scenario. The results are as follows. The petition has a negative effect on WTP values elicited in the drug scenario: a one-sided test rejects non-negativity with $p=.084$. The petition has no significant effect in the move scenario $(p=.316)$, either positive or negative. The impact of the petition in the regulation scenario is positive and significant: a one-sided test strongly rejects non-positivity of the effect with $p=.017$. The percentage changes in WTP values induced by the petition in the drug, move and regulation scenarios are presented in Figure 1 and are $-26.72 \%$, $17.55 \%$ and $38.69 \%$ respectively.

\section{Discussion}

In this field experiment, we shed new light on the consumer/citizen distinction often used in the literature to explain respondents' answers in CV surveys. We do so by giving respondents the opportunity to behave politically - by signing a petition about protection of the environment - prior to a standard CV questionnaire dealing with air pollution using three different scenarios. Inspired by social psychology research, we argue that signing the petition is likely to induce an attitude more oriented toward environmental protection by turning subjects into citizens concerned with environmental protection. Accordingly, we suggest that signing the petition should have a positive impact on willingness to pay values in the regulation and move scenarios (first hypothesis) but a negative one in the drug scenario. This is because the drug scenario does not protect 
the environment in any strict sense and is therefore incompatible with being a citizen committed to environmental protection (second hypothesis). Moreover, the impact of signing the petition should be greater in the regulation scenario than in the move scenario because the regulation scenario is much more closely related to the petition (third hypothesis).

Having presented in the previous section a number of results, via unconditional tests and econometrics, we will now comment on them further, highlighting certain results. First, there is a low number of protest responses in our sample $(7.8 \%$ for the whole sample). This result is in line with what Chanel et al. (2006) found using a similar valuation procedure also dealing with air pollution and based on the same referent population. The petition has no significant impact on the protest responses in our sample, whatever the scenario considered. The petition is therefore not a determinant of respondents' agreeing to participate in the valuation exercise. Since up to ninety percent of subjects agreed to pay that control groups without petition, it would have been surprising to find that the petition had an impact on protest responses. Second, committed citizens, that is, subjects who signed the petition, are more likely to pay more in the move and regulation scenarios (although the effect is not significant in the move scenario). Our first hypothesis is therefore partly supported by our sample. The effect of the petition on willingness to pay values elicited in the drug scenario is negative, therefore in accordance with our second hypothesis. The strongest positive effect of the petition is found in the regulation scenario and this supports our third hypothesis.

How do our results relate to previous findings? Experimental studies show that invoking moral values or responsibility indeed increases individuals' willingness to pay. For instance, Boyce et al. (1992) induce a moral dimension in a valuation experiment by destroying unsold goods (small Norfolk Island pine trees). If the subject submits a bid to purchase the tree lower than the selling price (unknown by the subject when s/he submits his/er bid), the pine tree is "killed" by the experimenter. They show that subjects endowed with a moral responsability, that is in the 'kill' experimental condition, pay more than in the 'no-kill' condition (where unsold goods are not destroyed). In a paired comparison study, Clarke et al. (1999) show that when the decision is 
on the sole responsibility of the subject ${ }^{17}$ the values obtained for environmental public goods are higher as compared to a situation where the decision is shared between subjects. This is what we, too, obtain in the move and regulation scenarios. Our experimental findings, as well as previous findings, are compatible with the view that the respondent adopts a social welfare perspective when $\mathrm{s} / \mathrm{he}$ acts as a citizen (rather than considering his/er own private interest only when $\mathrm{s} /$ he acts as a consumer). Such a respondent will have a higher willingness to pay such as in Nyborg (2000)'s model because s/he cares about the welfare of others when s/he acts as a citizen.

Results however differ for the drug scenario, where subjects who have signed the petition tend to express lower willingness to pay values. This behavior cannot be explained by considering that subjects who act as citizen adopt a social welfare perspective because welfare of other members of the society is not considered in this scenario (remember that the $d r u g$ scenario involves only personal health benefits). We rather argue, based on the theory of commitment borrowed from social psychology, that the petition in our experiment has induced a commitment to environmental preservation. Taking the drug would mean decreasing the health effects of air pollution but not protecting the environment, and this is incompatible with being a citizen who is concerned about environmental protection. This incompatibility between the $d r u g$ scenario and the attitudes of respondents as citizens would explain the decrease in stated willingness to pay.

\section{Conclusion}

Does the consumer/citizen distinction matter in stated preferences surveys? First, our results suggest that respondents would give a different answer depending on whether they reason from a consumer or citizen perpective. Second, the sign and the size of the effect on stated willingness to pay of being a citizen rather than a consumer depend on the (in)compatibility and the degree of similarity between attitudes as a citizen and the hypothetical scenario implemented in the survey. 
What are the consequences of these findings for the use of stated preferences methods in public decision making? If cost-benefit analysis is interpreted as a market simulation, practionners of $\mathrm{CV}$ would favour the consumer perspective (Sugden 2005). However, our results indicate that respondents may adopt a citizen perspective even in a typical consumer perspective scenario, such as in the drug scenario in our study. The hypothetical scenario alone may therefore not guarantee that respondents answer as consumers to the willingness to pay question. Hence, one may want to identify respondents who act as citizens. To this end, the real meaning of "monetary values" can be analysed by using attitude questions that can be correlated to willingness to pay values (see for instance Blamey, Common, and Quiggin 1995; Blamey 1998; Nunes and Schokkaert 2003). We argue that questions which investigate past behaviour of respondents as citizens (such as belonging to an environmental association or to a union, or having signed a petition,...) should also systematically be added to the analysis.

How do we then account for willingness to pay of respondents acting as citizens? One the one hand, one may remove these answers from the analysis because "adding personal and social values is like adding apples and oranges" (Nyborg 2000, p.319). Another alternative would be to argue that what matters is the willingness to pay at the moment of decision (Sugden 2007). To follow this route, consider a person who enters a furniture shop to have a look around but with no clear intention to buy anything right now. When s/he enters, the salesman offers him/er a coffee and suggests $\mathrm{s} /$ he may sit on a sofa $\mathrm{s} /$ he was looking at. The person accepts the coffee and sits down on the sofa. Research in social psychology evoked sooner in this paper explains that the invitation of the salesman is a typical foot-in-the-door technique (of which the salesman may be aware or not). This technique dramatically increases the probability that the person effectively buys the sofa. Proponents of willingness to pay at the moment of decision approach would certainly consider that this purchase is a valid economic decision and it is this purchase that should be taken into account if the government were to consider subsidizing national sofa production. ${ }^{18}$ However, if this is accepted, then so should the idea that the willingness to pay of our committed citizens can be taken into account for public policy. 


\section{References}

Alberini, A., M. Cropper, A. Krupnick, and N. Simon (2004). Does the value of a statistical life vary with age and health status? Evidence from the US and Canada. Journal of Environmental Economics and Management, 48, 769-792.

Aprahamian, F., O. Chanel, and S. Luchini (2007). Modeling starting point bias and unobserved heterogeneity in contingent valuation surveys: an application to air pollution. American Journal of Agricultural Economics, 82, $533-547$.

Bem, D.J. (1972). Self-perception theory. In L. Berkowitz (Ed.), Advances in experimental social psychology, Volume 6. New York: Academic Press.

Bishop, R. and R.T. Woodward (1995). Valuation of environmental amenities under certainty. In D.W. Bromley (Ed.), Handbook of Environmental Economics, pp. 543-667. Oxford: Blackwell Publishers.

Blamey, R.K. (1998). Decisiveness, attitude expression and symbolic responses in contingent valuation surveys. Journal of Economic Behavior \& Organization, 34, 577-601.

Blamey, R., M. Common, and J. Quiggin (1995). Respondents to contingent valuation surveys: consumers or citizens. Australian Journal of Agricultural Economics, 39, 263-88.

Bodner, R. and D. Prelec (2001). Self-signaling in a neo-calvinist model of everyday decision making. In J. Carillo and I. Brocas (Eds.), Essays in Psychology and Economics. Oxford University Press.

Boyce, R.R., T.C. Brown, G.H. McClelland, G. Peterson, and W.D. Schulze (1992). An experimental examination of intrinsic values as a source of the WTA-WTP disparity. American Economic Review, 82, 1366-1373.

Burger, J. (1999). The foot-in-the-door compliance procedure: A multipleprocess analysis and review. Personality and Social Psychology Review, 3, 303-325.

Camerer, C., S. Issacharoff, G. Loewenstein, T. O’Donague, and M. Rabin (2003). Regulation for conservatives: behavioral economics and the case 
for 'asymmetric paternalism'. University of Pennsylvania Law Review, 151, $1211-1254$.

Chanel, O., S. Cleary, and S. Luchini (2006). Does public opinion influence WTP? Evidence from the field. Applied Economics Letters, 13, 821-824.

Clarke, A., P. Bell, and G. Peterson (1999). The influence of attitude priming and social responsability on the valuation of environmental public goods using paired comparisons. Environment and behavior, 31, 838-857.

Davidson, R. and J. MacKinnon (1993). Estimation and Inference in Econometrics. Oxford University Press.

Desaigues, B., D. Ami, M. Hutchison, A. Rabl, S. Chilton, H. Metcalf, A. Hunt, R. Ortiz, S. Navrud, P. Kaderjak, R. Szántó, N.J. Seested, C. Jeanrenaud, S. Pellegrini, K. M. Braun, M. Scasny, V. Máca, J. Urban, M.-E. Stoeckel, A. Bartczak, O. Markiewicz, P. Riera, and V. Farreras (2007, February). Final report on the monetary valuation of mortality and morbidity risks from air pollution. European Union, Technical report. Deliverable D6.7, NEEDS RS1b.

Freedman, J. L. and S.C. Fraser (1966). Compliance without pressure: the footin-the-door technique. Journal of Personality and Social Psychology, 4, $195-202$.

Girandola, F. and N. Roussiau (2003). L'engagement comme source de modification à long terme. Les Cahiers Internationaux de Psychologie Sociale, 57, 83-101.

Hausman, J. A. (Ed.) (1993). Contingent Valuation : A Critical Assessment, Contribution to Economic Analysis, Volume 220 of Contribution to Economic Analysis. North-Holland.

Heckman, J.J. (1979). Sample selection bias as a specification error. Econometrica, 47, 153-162.

Joule, R.V. and J.L. Beauvois (1998). La soumission librement consentie. Paris: Presses Universitaires de France.

Joule, R.V., F. Girandola, and F. Bernard (2007). How can people be induced to willingly change their behavior? The path from persuasive communication to binding communication. Social \& Personality Psychology Compass, 1, 493-505. 
Kahneman, D. and R. Sugden (2005). Experienced utility as a standard of policy evaluation. Environmental \& Resource Economics, 32, 161-181.

Katzev, R. and T. Wang (1994). Can commitment change behavior ? A case study of environmental actions. Journal of Social Behavior and Personality, 9, 13-26.

Kennedy, P.E. (1981). Estimation with correctly interpreted dummy variables in semilogarithmic equations. American Economic Review, 71, 801.

Kiesler, C.A. (1971). The psychology of commitment. Experiments linking behavior to belief. New York: Academic Press.

Kiesler, C.A. and J. Sakumura (1966). A test of a model for commitment. Journal of Personality and Social Psychology, 3, 349-353.

Krupnick, A., A. Alberini, M. Cropper, N. Simon, B. O’Brien, R. Goeree, and M. Heintzelman (2002). Age, health and the willingness to pay for mortality risk reductions: a contingent valuation study of Ontario residents. Journal of Risk and Uncertainty, 24, 161-186.

Künzli, N., R. Kaiser, S. Medina, M. Studnicka, O. Chanel, M. Herry, F. Horak, V. Puybonnieux-Texier, P. Quenel, J. Schneider, R. Seethaler, J.-C. Vergnaud, and H. Sommer (2000, September). Public-health impact of outdoor and traffic-related air pollution: a European assessment. Lancet, 356, 795-801.

Lewinson-Zamir, D. (1998). Consumer preferences, citizen preferences, and the provision of public good. The Yale Law Journal, 108, 377-406.

Nunes, P.A.L.D. and E. Schokkaert (2003). Identifying the warm glow effect in contingent valuation. Journal of Environmental Economics and Management, 45, 231-245.

Nyborg, K. (2000). Homo economicus and homo politicus: interpretation and aggregation of environmental values. Journal of Economic Behavior \& Organization, 42, 305-322.

Orr, S.W (2007). Values, preferences, and the citizen-consumer distinction in cost-benefit analysis. Politics, Philosophy \& Economics, 6, 107-130.

Pallack, M., D. Cook, and J. Sullivan (1980). Commitment and energy conservation. Applied social psychology annual, 1, 235-253. 
Sagoff, M. (1988). The Economy of the Earth. Cambridge: Cambridge University Press.

Sugden, R. (2005). Coping with preference anomalies in cost-benefit analysis: a market simulation approach. Environmental and Resource Economics, 32, 129-160.

Sugden, R (2007). Cost-benefit analysis as market simulation: A new approach to the problem of anomalies in environmental evaluation. Resources for the future discussion paper. RFF DP 07-28-REV.

Viscusi, W., W.A. Magat, and A. Forrest (1988). Altruistic and private valuations of risk reduction. Journal of Policy Analysis and Management, 7, $227-245$.

Wang, T.H. and R.D. Katzev (1990). Group commitment and resource conservation : two field experiments on promoting recycling. Journal of Applied Social Psychology, 20, 265-275. 


\section{Notes}

${ }^{1}$ Here, we mean by political behaviour a behaviour relying on social preferences.

${ }^{2}$ This argument stems from self-attribution theory (Bem 1972) and is central to selfsignaling models in economics. In self-signaling models, agents derive utility from the outcome of actions, outcome utility, but also derive diagnostic utility from the information that the action provides on some underlying trait or disposition of themselves (see for instance Bodner and Prelec 2001).

${ }^{3}$ In their real experiment, Freedman and Fraser (1966) telephoned housewives in Palo Alto, California. They asked them if they would be willing to answer a few questions about the kind of soaps they used. Two or three days later, the subjects were asked if they would agree to have five or six men come to their house for two hours or so to classify the household products they used. In the control group, only the second request was made. In the control $22.2 \%$ accepted, while with foot-in-the-door, $52.8 \%$ accepted.

${ }^{4}$ Long-term health effects of air pollution data are derived from current air pollution in Marseilles. Note also that our approach differs from Alberini et al. (2004) and Krupnick et al. (2002). When they present the new drug to respondents, they do not refer explicitly to air pollution - the drug is only associated with a reduction in mortality risks. In that sense, their approach is non-contextual.

${ }^{5}$ The scenario may also involve indirect benefits to the extent to which relatives of the subject can also benefit from his or her better health.

${ }^{6}$ Air quality in Marseilles, the largest city in the area, was used as a referent for all respondents.

${ }^{7}$ Here again, air quality in Marseilles was used as a referent.

${ }^{8}$ We chose to introduce the petition only on the second day in order not to contaminate the sessions without the petition. Three other sessions related to other topics were implemented in between.

${ }^{9}$ The presidential election was to be held 6 months later. At the time of the experiment, a petition, promoted in the French media, was actually circulating in France. Our petition was effectively sent to each candidate.

${ }^{10}$ When we were unsure whether or not certain subjects had signed the petition, they were identified later using the video system of the voting room.

${ }^{11}$ Information was presented simultaneously on individual screens and aloud to ensure that all respondents had the same information. It was based on epidemiological data on long-term 
mortality and morbidity risks induced by air pollution (Künzli et al. 2000). In the move and regulation scenarios, we also reminded subjects of the non-health effects of air pollution.

${ }^{12}$ For instance: "I do not agree with the principle of paying", "I would not pay since I will only move to live in the country", "I do not agree to pay to move to a less polluted place when I can die tomorrow crossing the street" or "I do not want to pay because the factories are the major polluters").

${ }^{13}$ WTP statistics are computed using non-protest responses only.

${ }^{14}$ In the following, unconditional mean tests are two-sided.

${ }^{15}$ The model is estimated in Stata 9.0 and $p$-values are computed using the robust variancecovariance matrix. Some observations are dropped from the analysis due to missing values, mainly on income. We also estimate a Box-Cox linear model where the WTP is transformed according to a Box-Cox transformation (see Davidson and MacKinnon 1993). Tests on the estimated transformation parameter $(\theta=.0208)$ reject equality to one $(p<.0001)$ or minus one $(p<.0001)$ but fail to reject nullity $(p=.547)$, that is using the logarithm of the WTP. In doing so, we however lose some observations, that is, true zero WTP, 11 observations hence $2.72 \%$ of the sample. We also exclude protest responses (34 subjects $-7.8 \%$ of the total sample). As we only consider subjects who agreed to sign the petition (when given the opportunity) and subjects who gave a strictly positive WTP, we also test for potential selection biases that would undermine our previous results. We do so by estimating Heckman selection models (Heckman 1979), first considering the selection of subjects and then, in a second equation, estimating the WTP model. We introduce into the selection equation the same covariates as in the WTP equation (covariates in the WTP equation are kept the same). Wald tests of independent equations show that there is no selection bias induced by protest responses $(p=.2972)$, nor for subjects who did not sign the petition $(p=.923)$ - the joint test is $p=.491$.

${ }^{16}$ Because the WTP equation is semilogarithmic, the percentage changes in WTP values induced by the petition are computed as per Kennedy (1981).

${ }^{17}$ The subject is told that $\mathrm{s} /$ he has been randomly selected to make the decision for all other participants.

${ }^{18}$ So called "assymetric paternalists" (see, for instance, Camerer et al. 2003) may not be happy with this behavioural approach that induces people to make purchases without their prior intention and hence would contest the validity of the consumer surplus' evaluation based on those purchases. Arguing pro or contra assymetric paternalism however is beyond the scope of this paper. 


\section{A Scenario 1: Drug scenario}

You are going to be the main actor in our scenario. You will have to take the best decision for yourself and your household.

Let's imagine that the Ministry of Health has authorized a new drug, different from those currently available. It allows the long-term effects of air pollution exposure to be reduced by half. It simply involves taking a pill every month, which, by the combined action of several vitamins, stimulates immunological responses. It has no side effects and no contra-indications. It can be taken by any person who is more than 5 years old.

This new drug is reimbursed neither by the social security system nor by the CMU (state means-tested health cover) nor by the complementary health insurances policies. This implies that, if you choose to buy it, you will bear the full cost. We would like to know how much you would be willing to pay to use this drug, which would reduce by half the long-term diseases and mortality risks associated with air pollution. Do not forget that this money will be drawn from your household's budget! You will therefore have less money at the end of the month for consumption or savings.

\section{B Scenario 2: Move scenario}

You are going to be the main actor in our scenario. You will have to take the best decision for yourself and your household.

Let's imagine that you and your household have to move. You can choose between two cities which are exactly equivalent in terms of inhabitants, working conditions, schools, climate, public services, cultural life, transport, housing, surroundings, etc. There is only one difference between them: the level of atmospheric pollution. The first city - let's call it POL - is as polluted as Marseilles. And the second city - let's call it LESSPOL - is half as polluted as Marseilles. 
The problem is that the cost of living is higher in LESSPOL (the less polluted city): housing, local taxes, public transport, etc. are more expensive. This means that if you choose to move to LESSPOL, you will have to pay more to have the same standard of living as in POL.

We would like to know how much you would be willing to pay per month for you and your household to move to LESSPOL (the less polluted city) rather than to POL (the town as polluted as Marseilles). Do not forget that this money will be drawn from your household's budget! You will therefore have less money at the end of the month for consumption and savings.

\section{Scenario 3: Regulation scenario}

You are going to be the main actor in our scenario. You will have to take the best decision for yourself and your household.

Let's imagine that new laws and rules are to be adopted to limit air pollution. Therefore industries, manufacturers of consumer products, public or private transport, will have to adopt less polluting technologies. Studies have shown that these new laws and rules will make it possible to reduce by half the number of highly polluted days in the PACA region, and particularly in Marseilles.

The implementation of these new technologies will induce higher costs in every-day life: energy, food and other goods, transport. This means that you will have to pay more to enjoy the same standard of living as before the implementation of these new laws and rules.

We would like to know how much you would be willing to pay per month for these new laws and rules to be implemented. Do not forget that this money will be drawn from your household's budget! You will therefore have less money at the end of the month for consumption and savings. 


\section{Petition}

Soon, all the candidates for the next presidential election will be known. You may know that for several days, since a few days, a petition has been circulating in France. The aim of this petition is to obtain a commitment from each candidate, whatever his/her political background, to include the questions of environmental conservation in his/er program, because it is important that each of us is able to make informed choices.

We need a lot of signatures. Therefore, if you think, like us, that issues of environmental conservation are essential issues on which candidates for the presidential election should take a clear stance, we invite you to sign this petition. Thank you. 


\section{E Sample characteristics}

\begin{tabular}{|c|c|c|c|}
\hline Variable & Description & Mean & (sd) \\
\hline Male & Subject is male $(=1)$ & .369 & $(.48)$ \\
\hline $\log (A g e)$ & Logarithm of age of the subject (years) & 3.612 & $(.35)$ \\
\hline $\log ($ Ners $)$ & $\begin{array}{l}\text { logarithm of number of persons } \\
\text { in the household }\end{array}$ & .825 & $(.52)$ \\
\hline $\log ($ Income $)$ & $\begin{array}{l}\text { Logarithm of Monthly individual } \\
\text { income (euros) }\end{array}$ & 7.042 & $(.89)$ \\
\hline Bac & $\begin{array}{l}\text { Senior high school education } \\
\text { level and higher }(=1)\end{array}$ & .750 & $(.42)$ \\
\hline PrivHealthIns & $\begin{array}{l}\text { Subject has private health } \\
\text { insurance }(=1)\end{array}$ & .819 & $(.39)$ \\
\hline LiveMars & Subject lives in Marseilles $(=1)$ & .762 & $(.43)$ \\
\hline Owner & $\begin{array}{l}\text { Status of the occupant of the } \\
\text { place of residence }(=1)\end{array}$ & .461 & $(.50)$ \\
\hline Smoker & Subject is a smoker $(=1)$ & .131 & $(.34)$ \\
\hline KnowAir & $\begin{array}{l}\text { Subject declares a good } \\
\text { knowledge of air pollution }(=1)\end{array}$ & .263 & $(.44)$ \\
\hline KnowAtmo & $\begin{array}{l}\text { Subject knows the ATMO official scale } \\
\text { of air pollution levels }(=1)\end{array}$ & .217 & $(.41)$ \\
\hline KnowAirmaraix & $\begin{array}{l}\text { Subject knows the AIRMARAIX local } \\
\text { air pollution index }(=1)\end{array}$ & .263 & $(.44)$ \\
\hline GoodQualiMars & $\begin{array}{l}\text { Subject says that the air quality in } \\
\text { Marseilles is good or very good }(=1)\end{array}$ & .054 & $(.23)$ \\
\hline NevSortWaste & Subject never sorts his/er waste $(=1)$ & .200 & $(.39)$ \\
\hline$H a b$ & $\begin{array}{l}\text { Subject changes habits during } \\
\text { highly polluted days }(=1)\end{array}$ & .570 & $(.491)$ \\
\hline FreshAir & $\begin{array}{l}\text { Subject regularly goes to } \\
\text { the countryside to breath pure air }(=1)\end{array}$ & .825 & $(.37)$ \\
\hline GoodHealth & $\begin{array}{l}\text { Subject declares good or } \\
\text { very good health }(=1)\end{array}$ & .713 & $(.44)$ \\
\hline
\end{tabular}

Table 3: Descriptive statistics 